\section{Correction}

In theMarch/April2004 TechTrends 48(2) we introduced an error into one of the figures (Figure 1) accompanying the "The strategic impact model: An integrative approach to performance improvement and instructional systems design" by Molenda and Pershing. On the right side of the model the title, "Performance interventions
- other than instructional" should have read "Performance interventions - instructional."

The typographical error was small but very consequential. The whole point of having the two "wings" of the model is to illustrate the two contrasting domains: instructional and non-instructional interventions. The right wing of the model depicts the processes associated with instructional development; the left wing depicts the processes associated with all of the types of performance interventions "other than" instruction.

We reprint the figure in its entirety here for the sake of clarity and for readers who may wish to substitute the correct version into their copies of the original article.

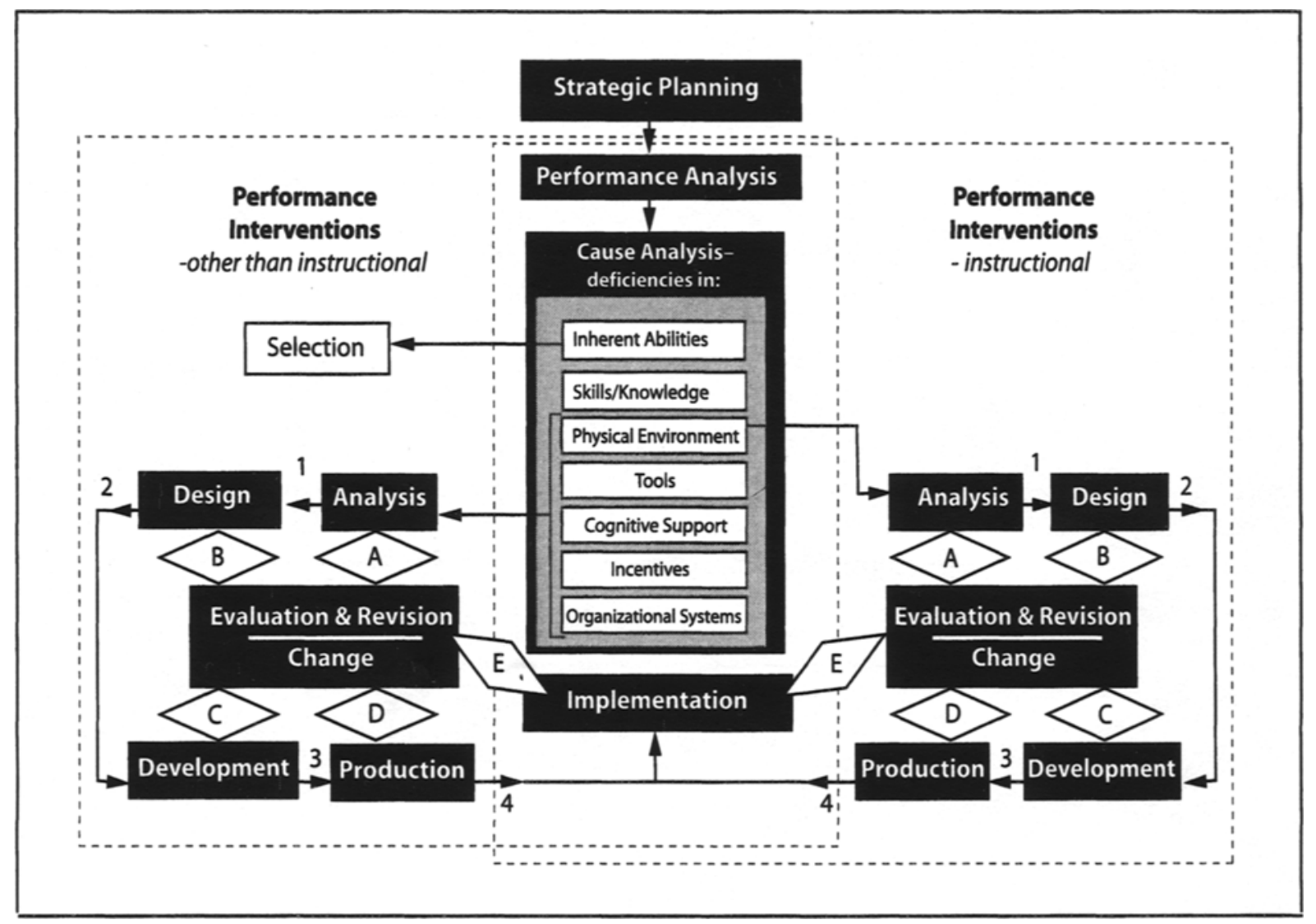

Figure 1: Strategic Impact Model @2003 J. Pershing of M. Molenda

\title{
Reviewers for 2004
}

TechTrends thanks the following individuals who assisted our Consulting Editors by completing manuscript reviews during 2004:

Joanne Beriswill

Doris Bollinger

Curtis Bonk

Abbie Brown (ID Portfolio)

Thomas Brush

Betty Collis

Michael Corry
David Diaz

Dolores Fidishun

Theodore Frick

Krista Glazewski

David Goodrum

Charles Graham

Chris Hebb
Lawrence Hinman

Yu-chen Hsu

Jerrold Kemp

Tiffany Koszalka

Linda Lohr (ID Portfolio)

Al Mizell

Michael Molenda
Trena Paulus

James Pershing

Rick Schwier (ID Portfolio)

Walt Wager

David Wiley

Lisa Yamagata-Lynch 